\title{
Laboreal
}

Volume $2 \mathrm{~N}^{\circ} 2$ | 2006

Varia

\section{Ergonomia, Pierre Falzon (Ed.)}

\author{
Laerte Idal Sznelwar
}

\section{OpenEdition}

Journals

\section{Edição electrónica}

URL: http://journals.openedition.org/laboreal/13400

DOI: $10.4000 /$ laboreal. 13400

ISSN: 1646-5237

\section{Editora}

Universidade do Porto

Refêrencia eletrónica

Laerte Idal Sznelwar, «Ergonomia, Pierre Falzon (Ed.) », Laboreal [Online], Volume 2 N² | 2006, posto online no dia 01 dezembro 2006, consultado o 23 setembro 2020. URL : http://

journals.openedition.org/laboreal/13400; DOI : https://doi.org/10.4000/laboreal.13400

Este documento foi criado de forma automática no dia 23 setembro 2020.

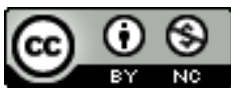

Laboreal está licenciado com uma Licença Creative Commons - Atribuição-NãoComercial 4.0 Internacional. 


\title{
Ergonomia, Pierre Falzon (Ed.)
}

\author{
Laerte Idal Sznelwar
}

\section{REFERÊNCIA}

Falzon, P. (Ed.) (2006). Ergonomia. São Paulo : Edgard Blücher, (edição aumentada do livro :)

1 Esse livro, fruto de um trabalho exaustivo de seu coordenador e dos diversos autores que o construíram, pode ser considerado com um novo marco, pois traz no seu conteúdo uma síntese relativa a temas diversos e importantes para a ergonomia. Nesta versão em português, encontramos em seus capítulos quarenta provenientes da edição original em francês (Falzon, 2004) e mais quatro adicionados. Adquirimos com esta obra uma fonte de conhecimento para todos interessados no desenvolvimento de suas ações profissionais, no ensino, nas pesquisas e, nos debates na sociedade sobre as questões do trabalho.

Quando se trata do desenvolvimento da ergonomia, busca-se uma maior inserção no mundo da produção com o objetivo de entender e para construir soluções para a ampla gama de problemas que fazem parte do dia a dia de trabalhadores em todos setores da economia. Encontramos aqui subsídios para compreender questões da atividade do trabalho, sejam elas relativas à metodologia ou a aspectos gerais, muito significativos com relação a paradigmas sobre o trabalho humano. O livro contém uma base importante de informações e, sobretudo de material para reflexões e para busca de soluções em áreas muito distintas, como a concepção de programas de computador, o trabalho de mediação e intervenção social, a arquitetura e a construção civil, a agricultura, entre outras. $O$ espectro de questões tratadas no livro engloba ainda a variabilidade de populações, pois trata de problemas muitas vezes esquecidos no mundo da produção, mas que estão cada vez mais presentes no espaço público, como a preocupação com o envelhecimento, com pessoas que têm necessidades especiais e, com a questão de gênero. De uma maneira mais específica, após ter sintetizado as diferentes partes e capítulos do livro - de modo a transmitir uma idéia mais precisa dos 
seus conteúdos e respeitando por isso a sequência de apresentação dos diferentes contributos - iremos realçar alguns aspectos desta interessante obra coletiva.

3 No início, Pierre Falzon nos propõe a leitura do livro trazendo no prefácio alguns tópicos para ajudar o leitor a compreender a proposta. Ele critica as visões mais estreitas sobre a ergonomia, principalmente aquelas que buscam reduzir o seu escopo de preocupações a um campo restrito, como a ergonomia ligada a aspectos físicos do trabalho. A partir de uma visão da história recente da ergonomia ele propõe que o livro seja visto como uma visão generalista onde é possível encontrar variadas dimensões da ergonomia, a de seus domínios de pesquisa, a de sua metodologia e, possíveis aplicações.

4 Ao trilhar a lista de autores e o sumário dos capítulos podemos já ter uma idéia da dimensão da obra e do escopo por ela proposto. É interessante reforçar que há, entre os autores, ao menos, três gerações de pessoas ligadas à ergonomia e que, em sua grande maioria, se não todos, estão alinhados com a proposta da ergonomia da atividade. Dentre os autores, há aqueles que provavelmente foram professores de quase todos os participantes da obra e, de muitos que fizeram seus estudos na França. Infelizmente, por não estar mais conosco, Alain Wisner não escreveu para esse livro. Por outro lado, a sua presença se faz sentir, não apenas em citações nos capítulos, mas também pelo seu pensamento que se faz presente direta ou indiretamente. A presença de textos de Antoine Laville, não mais presente entre nós, de Jacques Leplat e Maurice de Montmollin é muito significativa quando pensamos nos pilares da ergonomia da atividade. Evidentemente que na lista de autores não constam todos aqueles que tem contribuído de maneira significativa para o avanço da ergonomia na França e, em outros paises. Fica aí uma sugestão para a continuidade deste livro, talvez como uma possibilidade de incluir ainda mais autores e temas que constroem esse domínio tão fascinante do conhecimento e das ações humanas.

Em seu capítulo inicial, na primeira parte do livro, Pierre Falzon propõe uma introdução à disciplina acentuando as suas definições e a importância de algumas obras que tiveram um papel significativo na fundação e na construção desta linhagem em ergonomia. Ressalte-se a importância significativa da contraposição aos modelos dominantes nas décadas de 40-50 no mundo da produção e nas universidades, quando pouco se conhecia ou até mesmo se desdenhava o papel significativo dos sujeitos para o sucesso da produção, muitas vezes em detrimento de sua saúde. Infelizmente, apesar de toda essa trajetória da ergonomia moderna, ainda há muita prevalência de pensamentos errôneos sobre o trabalho e sobre a importância de um trabalho adequado, interessante, desafiador, promotor de saúde e de competências para os trabalhadores. Ainda neste capítulo há referências significativas com relação aos campos de especialização, às possibilidades de aplicação e às fontes de conhecimento em ergonomia. Com relação às práticas em ergonomia ou autor propõe uma distinção como atividades de diagnóstico e intervenção, como processos de resolução de problemas mal definidos e como atividade de resolução colaborativa. Conceitos fundamentais em ergonomia, como a distinção entre tarefa e atividade são tratados neste capítulo. $O$ autor propõe uma leitura interessante relativa a esses conceitos incluindo algumas distinções, como na questão da tarefa prescrita, aquilo que é explícito e o que é implícito. Ainda discute aquilo que é compreendido, aquilo que é apropriado, constituindo a tarefa efetiva. Sob o ponto de vista da atividade, Falzon dá relevância para a regulação, seja ela como um processo de retro-alimentação longa ou 
curta, ou ainda, distinguindo como uma questão de sistema ou da atividade propriamente dita. Discute ainda as conseqüências das atividades com relação à saúde $\mathrm{e}$ à aquisição de competências.

6 Antoine Laville nos propõe uma viagem na história da ergonomia, na sua vertente francofônica. Esse capítulo é fruto de um longo trabalho que ele desenvolveu, quiçá o seu último, onde ele se propôs a partir de levantamentos feitos em extensa documentação, de entrevistas, discussões e muita conversa com seus colegas, com alunos, e com diferentes atores sociais, constituir a história, que em boa parte ainda estava e está acontecendo. Indo mais alem da ergonomia propriamente dita, o autor faz referencias à história do trabalho e sua relação com o desenvolvimento das técnicas e do conhecimento. Sobretudo, faz referencia à questão da saúde, infelizmente trilhada a partir dos acidentes e das doenças. Ainda sem poderem ser chamados explicitamente de ergonomistas, ele cita inúmeros autores, que desde há muito tempo (ele cita explicitamente a idade média, o renascimento) seguidos de cientistas mais modernos, têm procurado entender e propor melhorias no trabalho. Há, nesse texto, várias referências ao desenvolvimento da ergonomia moderna, principalmente na França e na Bélgica, berços da ergonomia da atividade. Ele nos propõe uma reflexão que comporta aspectos relativos à questão campo / laboratório, ao campo de atuação da ergonomia, englobando somente o posto de trabalho ou se estendendo a questões organizacionais e, ainda com relação ao equilíbrio necessário entre as questões de saúde e de produtividade.

7 Com relação à proximidade da ergonomia com outras disciplinas, Jacques Leplat e Maurice de Montmollin nos propõem uma discussão sobre a autonomia e a especificidade da ergonomia e a sua constituição enquanto área de conhecimento e como profissão. Para os autores essa questão pode ser analisada sob dois pontos de vista, aquele que a considera como uma disciplina que tem contornos convencionais justificada mais por suas características de intervenção profissional, para a qual seriam utilizados os conhecimentos de ciências vizinhas, adotando portanto uma postura de interdisciplinaridade. $\mathrm{O}$ segundo ponto de vista acentua a especificidade da disciplina, para o qual, haveria paulatinamente a constituição de um saber especificamente ergonômico, com uma organização e uma lógica própria. Os conhecimentos e os métodos se adaptariam progressivamente a esta perspectiva. Os autores discutem as vantagens de cada ponto de vista e propõem um debate com algumas disciplinas que tratam, mesmo que de maneira parcial, do trabalho, como a biologia humana, a medicina do trabalho, as ciências cognitivas, a psicologia do trabalho, a sociologia do trabalho, a organização do trabalho e as ciências da gestão. Sem buscar a exaustão do tema, elas ainda mostram que haveria outras disciplinas que seria importante discutir, como as ciências da educação, a psicodinâmica do trabalho e as ciências da engenharia. Esse tipo de questionamento seria, segundo os autores, muito importante na formação de ergonomistas.

8 Ao iniciar a segunda parte do livro (Fundamentos teóricos e quadros conceituais), Françoise Dopler propõe uma discussão sobre "trabalho e saúde". No texto ela propõe uma leitura sobre o trabalho a partir de várias dimensões, como o seu lugar na vida ativa das pessoas, assim como a sua evolução mais recente. Faz menção a mudanças nos tempos do trabalho, no seu conteúdo, incluindo os problemas ligados à terceirização, aos fenômenos de intensificação e "densificação" do trabalho, assim como as novas formas de gestão, de prescrição, e das condições de trabalho. Ainda trata de questões 
demográficas, acentuando a importância das idades intermediárias na constituição das populações de trabalhadores, o problema da inserção no mercado de trabalho dos jovens e a importância crescente das mulheres no mercado de trabalho. Com relação à saúde ela mostra a evolução dos conceitos e dos diferentes problemas vivenciados pelos trabalhadores, numa perspectiva histórica. Propõe também uma leitura baseada numa tipologia onde estão incluídos os acidentes de trabalho, as patologias ligadas ao ambiente de trabalho, de sobrecarga física, de ordem psicológica, e a deterioração da saúde (patologias infra-clínicas). Por outro lado, faz menção, se apoiando em outros autores, à questão da construção da saúde como um processo de construção ao longo da vida, como fonte de plenitude, como fonte para o desenvolvimento de competências. Ela compara pontos de vista sobre a saúde oriundos da toxicologia, da medicina do trabalho, da psicodinâmica do trabalho, da clínica do trabalho e da ergonomia, no que diz respeito às suas diferenças e similaridades. Por fim, deixa a questão relativa à importância do trabalho como um mediador permanente na busca do sentido às nossas vidas.

Luc Desnoyers propõe no capítulo seguinte uma leitura sobre a questão da aquisição da informação. Ele discute a evolução dos conhecimentos na área, principalmente acentua a importância do ser humano como ativo na busca da informação e não apenas como um ser dotado de um fisiologia que captaria, através de órgão sensoriais as informações provenientes do ambiente, das máquinas. São discutidos pelo autor diversos aspectos ligados à obtenção de informação visual e a importância da ação do ergonomista para facilitar esses processos. A partir de vários estudos, mostra a importância das estratégias dos trabalhadores para obter informações, por exemplo, o que privilegiam e a distância com relação a um modo operatório prescrito. Para facilitar a ação dos trabalhadores seria necessário, portanto, projetar a iluminação utilizando as técnicas existentes em acordo com as necessidades operacionais e com as propriedades e limitações da visão. Discute ainda a importância das informações auditivas em relação às propriedades auditivas, assim como a importância do ruído não apenas como um risco à saúde, mas também como um risco para a captação da informação auditiva. Acentua a importância do conceito de escuta em oposição ao conceito da audição como um processo passivo. Ele ainda propõe o reconhecimento da importância da captação da informação através do tato, para o autor a obtenção da informação através das mãos é o resultado de uma atividade específica que também contribuiria para a condução do gesto.

Michel Millanvoye escreveu um capítulo sobre o ambiente físico e como tratar a questão da exposição dos trabalhadores ao ruído, à vibração, ao clima, à iluminação nos seus locais de trabalho. Para o autor, a análise das "ambiências físicas" seria necessária para completar as análises ergonômicas do trabalho e para ajudar a medir a exposição a agentes agressivos à saúde do trabalhador. 0 autor discute o fato que, apesar dos riscos, principalmente quando a exposição seja excessiva, os trabalhadores obtém informações sobre o estado dos dispositivos ou dos produtos que estão em processo. Essa relação entre exposição e aquisição de informações é para o autor importante ao se projetar modificações nos postos de trabalhos. Ainda Millanvoye propõe uma discussão sobre as estratégias para medição e como analisar os resultados de uma avaliação à exposição, acentuando a limitação das normas e a importância de se considerar esta questão numa perspectiva mais ampla onde as soluções não sejam apenas técnicas, mas incluam também aspectos organizacionais. 
11 O trabalho em condições extremas, é tratado pelos autores do capítulo sete do livro, Marion Wolff e Jean-Claude Spérandio, deveria, a todo custo ser evitado, pois estas situações seriam perigosas ou intoleráveis. Essas condições seriam toleráveis apenas em circunstâncias excepcionais e de pouca duração. Os autores discutem mais especificamente o assunto da termoregulação no trabalho sob fortes exigências térmicas, o trabalho em altitude, os ruídos muito elevados, o estresse e a manutenção prolongada dos períodos de vigília, sobretudo quando há uso de substâncias químicas estimulantes. Como conclusão os autores afirmam que o trabalho em situações extremas só pode ser aceito quando é inevitável e, além de durar pouco, só podem ser executados por pessoas selecionadas, acompanhadas no plano fisiológico e psicológico, alem de serem treinadas para tal tipo de atividade.

Trabalhar em horários atípicos é o tema proposto por quatro autores (Béatrice Barthe ; Charles Gadbois; Sophie Prunier-Poulmaire e Yvon Quéinnec). Neste capítulo é discutida a questão da necessidade que há na sociedade moderna para que diferentes tipos de empresas, em quaisquer setores da economia, operem em horários outros que aqueles considerados como mais tradicionais, como as oito horas diurnas. Para evitar efeitos nefastos para a saúde humana e responder às necessidades da produção, os autores propõem uma discussão baseada em vários estudos que consideram as características da temporalidade humana, os problemas de saúde já conhecidos e as repercussões sobre a eficiência, as experiências já existentes, além de propor uma metodologia para a elaboração de soluções aceitáveis. Há um desenvolvimento interessante de idéias relativas aos ritmos biológicos, correlacionando-os como os tempos da sociedade, da vida fora do trabalho e a dinâmica temporal das atividades no trabalho. Apresentam também diversos aspectos relativos à gestão dos conflitos causados pela discordância dos horários de trabalho com os outros tempos biológicos e sociais. Com relação às conseqüências, podemos dar evidência problemas do impacto econômico, aliás pouco estudados, ao lado de problemas de eficiência, de saúde, da desagregação familiar. Em algumas situações mostram que há também efeitos positivos, em alguns casos e para algumas pessoas. Com relação à metodologia para abordar a questão chamam a atenção para diversos aspectos, sobretudo para o envolvimento dos interessados, o acesso à informação, a negociação, a busca de várias alternativas numa mesma organização, o acompanhamento, a resolução de problemas que possam se apresentar e a aplicação de novos conhecimentos.

13 Para discutir a questão do envelhecimento e o trabalho, Antoine Laville e Serge Volkoff nos propõem uma reflexão que engloba um fenômeno crescente resultante do aumento da longevidade das populações e da duração da vida ativa. Outros aspectos das mudanças no cenário demográfico têm a ver com o aumento do tempo de escolaridade e o desemprego. Soma-se a tudo isso as crises financeiras dos sistemas previdenciários. Os autores apresentam uma síntese de resultados de pesquisas que discutem as conseqüências dos constrangimentos de tempo, a irregularidade e a imprevisibilidade dos horários e a instabilidade dos coletivos de trabalho, fatos que trazem grandes desafios para a ergonomia, principalmente para considerar de maneira mais abrangente a relação entre idade e trabalho. Se por uma lado mostram as dificuldades crescentes com relação à idade, principalmente no que diz respeito ao aumento de certas deficiências fisiológicas e cognitivas, mostram as possibilidades de regulação para a busca de novos equilíbrios, se a maneira como o trabalho é organizado permite e, também dos efeitos compensatórios da experiência. Discutem também questões ligadas 
aos processos de aprendizagem mostrando que há muito preconceito quando se diz que as pessoas mais idosas não conseguem aprender. Terminam o capítulo discutindo a amplitude desse campo de ação para a ergonomia, em seus aspectos físicos, cognitivos e, sobretudo porque não há uma linearidade no envelhecimento, como não há um determinismo com relação às perdas.

Cecília de la Garza e Elie Fadier discutem a questão da segurança e da prevenção propondo uma correlação com aspectos jurídicos e ergonômicos. Começam com um apanhado histórico sobre a questão, enfatizando as principais leis e fatos mais relevantes para a prevenção. Discutem a evolução do modelo francês e, o quanto este demorou para evoluir e, que apenas recentemente estaria previsto em lei um maior equilíbrio entre as exigências de produtividade e as de saúde/segurança. Discutem também a evolução dos conceitos de acidente que, a partir de um ponto vista, infelizmente ainda muito prevalente, onde os trabalhadores seriam a única causa dos acidentes, evoluiu, para outras visões que incorporam muitos conhecimentos oriundos da ergonomia e de outras áreas do conhecimento. Discutem as limitações do conceito de erro humano e mostram a importância da ação dos trabalhadores como fundamental para a garantia da confiabilidade dos sistemas. Sobretudo propõem uma discussão que se distancia de conceitos simplificadores da realidade e salientam o papel da análise da atividade, aliada a outras abordagens, para ajudar a compreender melhor os problemas e para se projetar sistemas-sociotécnicos mais seguros e confiáveis.

Um capítulo discutindo carga de trabalho e estresse é proposto por Pierre Falzon e Catherine Sauvagnac. Eles apontam a importância de se considerar as causas organizacionais do estresse que ajudariam a entender a prevalência desse sintoma no mundo moderno. Apontam para o fato de que a carga de trabalho e o estresse praticamente nunca foram abordados de maneira conjunta, assim como a relação destes problemas com o burn-out (sensação de esgotamento) e o assédio. Mostram que várias mudanças no trabalho moderno seriam os verdadeiros responsáveis por esses problemas, dentre elas as mudanças nas prescrições, como atingir metas ou ideais inatingíveis ; os fatores temporais, como a intensificação, as interrupções e os horários irregulares ; a precariedade do trabalho e o aumento das solicitações mentais. A seguir propõem uma discussão onde articulam os conceitos de carga, constrangimento e a mobilização dos operadores. Relacionam esses aspectos com a fadiga, seja física ou mental, com os modos operatórios e a sua regulação. Ainda discutem a relação entre as competências dos operadores e a complexidade das tarefas. Abordam a questão do estresse, a partir de modelos explicativos e dos riscos para a saúde e a proximidade com a questão do burn-out, que poderia ser uma de suas conseqüências, uma ruptura. A partir dessa proposta de articulação, terminam o capítulo propondo ações em ergonomia para identificar o problema e combater as causas do estresse.

o capítulo 12 é dedicado aos paradigmas e modelos para a análise cognitiva das atividades. Nele, Françoise Darses, Pierre Falzon e Christophe Munduteguy discutem o conceito de modelo e a sua utilidade para a análise e a ação ergonômica. Para eles os modelos devem ser explícitos e ajudam a acelerar o processo de análise e, apesar de sua grande utilidade, qualquer modelo tem seus limites. Discutem ainda a evolução da ergonomia, comportamental nos seus primórdios, evoluindo para uma abordagem baseada na atividade. Mostram o interesse dos paradigmas contemporâneos, da teoria da atividade, da ação e da cognição situadas. Reforçam a importância dos conceitos de cognição distribuída e de cognição socialmente distribuída, onde podem ser relevados 
os aspectos da disponibilidade das representações, da flexibilidade resultante na organização das atividades e da coordenação como um fenômeno emergente das interações entre membros de uma equipe. Propõe que para analisar a atividade cognitiva é necessário classificar os problemas, como os problemas de indução de estrutura (para o diagnóstico) e os problemas de transformação do estado (recuperação dos mal funcionamentos). A seguir discutem os problemas de concepção, que parte de um estado inicial mal definido para chegar em um processo de avaliação das soluções quando o artefato já está pronto. Esse processo passa também por fases intermediárias de avaliação dos projetos, de maquetes e de protótipos. Apresentam ainda três níveis de atividades cognitivas, baseadas em habilidades, em regras e em conhecimentos. Por fim discutem modelos de descrição do conhecimento procedimental, discutindo a sua importância, principalmente para a formular essa dimensão da ação.

A competência profissional e o seu desenvolvimento são tratados por Annie WeilFassina e Pierre Pastré. Tratam das definições de competência, sua relação com os conceitos de saber e de saber-fazer e a sua importância para desencadear uma determinada atividade. Mostram que a noção de competência engloba múltiplas dimensões, a questão de serem finalizadas, a possibilidade de desenvolvimento através da formação e da experiência, e o seu caráter explícito ou tácito (incorporado), assim como sua relação com as escolhas organizacionais. Discutem a relação entre o desenvolvimento das competências e a progressão na organização das ações e no processo de conceituação (como uma ferramenta para agir e pensar). Tratam de modelos cognitivos, isto é, como resposta ao como a coisa funciona e, de modelos operatórios que discutem como a se organiza a ação, em uma finalidade pragmática. Dentre outras questões ainda tratam dos processos de automatização das competências, a passagem da consciência à não consciência, um processo de transformação dos conhecimentos declarativos em procedurais. Ainda articulam esses conceitos com o de emergência do sentido. Tratam da questão do desenvolvimento das competências profissionais no longo prazo, mostrando inclusive como evoluem as estratégias com a aquisição de experiência. Discutem a evolução com relação à perspectiva temporal, as relações no trabalho coletivo e a aquisição de possibilidades para refletir sobre a situação e para resistir a perturbações existentes nos processos de produção. Propõem uma discussão sobre como ajudar a construção de competências, com a mediação humana, com a utilização de instrumentos, usando simulações e dispositivos de análise a posteriori, que permitam atividades de reflexão meta-funcional. Em conclusão, reafirmam o papel do ergonomista na identificação e na construção das competências.

No capítulo seguinte, Laurent Karsenty e Michele Lacoste discutem a questão da comunicação e o trabalho. A perspectiva que eles trabalham englobam aspectos da comunicação humana, mas também da comunicação homem-máquina, discutem a intensificação da comunicação no trabalho, as necessidades de investimento pessoal e o esforço para se comunicar, que coloca em jogo, as intenções, as crenças, os valores, as emoções, numa perspectiva do coletivo de trabalho. Há uma discussão importante relativa ao fato que essas questões ultrapassam o ponto de vista funcionalista, baseado no previsto nas tarefas, evoluindo, tanto no que diz respeito ao próprio conceito de informação, na questão da interatividade, das múltiplas funções da comunicação. Incluem ainda no debate a questão que essa problemática transcende o conteúdo do trabalho e a relação entre os trabalhadores, pois está ligada aos modos de organização. Para o ergonomista há várias vertentes que podem ser tratadas com relação à comunicação, como parte da atividade individual, como modo para realizar o trabalho, 
como ligação entre as pessoas, como condição para a eficácia dos coletivos, como recurso organizacional ou ainda como um tipo particular de atividade. Ainda é, proposta pelos autores, uma discussão sobre os campos de aplicação como, em situações de risco, na cooperação à distância, no trabalho cooperativo informatizado, em situações de concepção em atividades comerciais e de serviço. Terminam o capítulo discutindo algumas dimensões relativas ao formato e às modalidades da comunicação e chamando a atenção que esse campo é muito vasto e ainda há muito que pesquisar a respeito.

19 Viviane Folcher e Pierre Rabardel discutem a perspectiva instrumental relacionada a homens, artefatos e atividades. A discussão proposta mostra a evolução dos conceitos, incluindo pontos de vista, como o de interação, de um sistema homem-máquina, ou ainda de uma abordagem mediada. Indicam como as teorias da atividade permitem explorar a questão da mediação da atividade humana pelo artefato, e aí distinguem as mediações que permitem a aquisição de conhecimentos sobre o objeto e aquelas que visam a ação sobre o objeto, inclusive em uma perspectiva de orientação do sujeito para si mesmo e para os outros. Tratam do conceito que transforma o artefato em um instrumento, em um processo de apropriação, da gênese instrumental, orientada para aquele artefato ou ainda como parte de um sistema de instrumentos. Introduzem ainda o conceito do poder para agir. Finalmente propõem um ponto de vista que transforme o ponto de vista da concepção, evoluindo de uma concepção para o uso em direção a uma concepção durante o uso.

Jean-Michel Hoc discute a "cooperação" homem-máquina em situação dinâmica. Para o autor, mesmo que aliar o humano à máquina seja construir uma quimera, há um interesse particular nessa discussão, principalmente quando o controle do operador humano é parcial, o restante depende de mecanismos, de máquinas ditas "inteligentes". Há uma discussão sobre aspectos do trabalho cooperativo entre as pessoas mas também aspectos da convivialidade, da usabiliadade, da transparência em se tratando da repartição das funções entre os humanos e as máquinas. Discute o problema da responsabilidade legal ser do operador humano, quando se trata do desempenho do sistema e ainda que essa repartição de funções depende, ao menos em parte, das teoria cognitivas em voga. Ainda levanta aspectos relativos à perda de perícia, à aceitação ou contentamento, da confiança em si mesmo e nas máquinas e quanto à perda de adaptabilidade. Discute também aspectos da cooperação na ação e no planejamento, assim como de uma "meta-cooperação", entre outras questões. Conclui sobre a importância de desenvolver as ferramentas mantendo um referencial comum que reduza a carga de trabalho dos operadores.

21 A gestão dos riscos é apresentada por René Amalberti no capítulo 17 onde ele discute a relação com a gestão dos erros, propondo que se abandone uma visão simplista que buscaria a eliminação dos riscos e dos erros. 0 autor afirma que a passagem para o século XXI traz desafios consideráveis, pois mesmo em sistemas onde houve uma considerável redução dos erros ainda há problemas com acidentes, a própria definição do que seria um erro ainda é confusa, e a questão de condutas arriscadas é um tema central no debate, uma vez que algumas seriam necessárias para manter a produção. Ele propõe uma revisão das teorias e um redesenho de estudos para a segurança que contemplem, entre outros, aspectos da realidade complexa do mundo do trabalho, a maneira como os trabalhadores desenvolvem o seu trabalho a despeito dos erros e das falhas, a inexistência de uma solução ideal mas sim a possibilidade de gerir as situações. 
Os níveis de ação possível seriam no da planificação, no dos processos decisórios, no da execução propriamente dita, incluindo uma perspectiva dinâmica e organizacional da segurança. Finalmente o autor propõe que os níveis de análise em segurança não se limitem a uma perspectiva de níveis horizontais em uma organização, mas que se atente para aspectos como a propagação das decisões, das migrações das práticas e dos conceitos que embasam as decisões.

22 A questão de gênero e trabalho é tratada por Karem Messing e Céline Chatigny. As autoras chamam atenção para o fato que seria interessante em ergonomia considerar que o gênero pode moldar as representações relativas às capacidades humanas, a formação que é propiciada, a divisão sexual com relação à atribuição das tarefas, os modos operatórios e estratégias, a interação com a vida fora do trabalho e as representações sociais relativas às conseqüências do trabalho para a saúde. Há, nesses capítulo, amplas discussões sobre a divisão sexual das atividades, as exigências físicas, cognitivas e psíquicas das tarefas e sua relação com o gênero, como no que diz respeito a uma menor latitude de decisão para as mulheres e à alocação de mulheres em tarefas repetitivas e com menor possibilidade de aprendizagem. Discutem aspectos sociais e culturais que envolvem essa questão e algumas propostas para abordá-las. Ainda dão relevância para diferenças entre modos operatórios relativas às diferenças entre sexo que, apesar de existirem dados experimentais que mostrariam, por exemplo, que as mulheres seriam menos fortes, isto não teria muito significado científico ao ser transposto à realidade. Outras questões são apontadas, como a da situação familiar e as relações no trabalho coletivo. Terminam afirmando que alguns destes fatos podem ser considerados numa análise quantitativa nos traços da atividade em análises ergonômicas.

23 Yves Clot discute o sentido do trabalho, começando por uma apresentação da psicodinâmica do trabalho, onde o ponto de vista proposto é que o sujeito se confronta com a realidade do trabalho numa relação dialética entre sofrimento e prazer, onde se situaria a busca do sentido. A seguir traz considerações sobre a psicologia social do trabalho onde mostra que, assim como a psicodinâmica, aqui não se aceita o redução do sujeito a um operador, nesse caso o trabalho, seria fonte de subjetivação. Com relação à ergonomia, afirma que esta situa a atividade com relação à tarefa. Faz também referencia ao fato que a questão da subjetividade seria reconhecida por ergonomistas como um dos determinantes da atividade, transpondo a visão que esta se reduziria às seqüências operacionais da ação. A seguir propõe uma clínica da atividade, onde a atividade poderia ser vista como uma luta entre várias ações possíveis ou impossíveis. $O$ sentido estaria na raiz daquilo que motiva ou desmotiva os sujeito, poderia ser entendido numa discordância criativa entre ocupações e pré-ocupações. Discute ainda a questão relativa às expectativas dos sujeitos em relação com aquilo que não podem fazer, das histórias comuns dos coletivos de trabalho, que constituem os gêneros profissionais, que podem ser alvo de retoques e estilizações por parte dos sujeitos.

24 A terceira parte do livro é constituída de capítulos que abordam a questão da metodologia e das modalidades de ação em ergonomia.

25 François Daniellou e Pascal Béguin escreveram um capítulo sobre a metodologia da ação ergonômica quando discutem as abordagens do trabalho real. Apontam que a construção da ergonomia tem a ver com uma tentativa de corrigir um desequilíbrio existente no mundo da produção entre a fabricação das máquinas e dos organogramas com relação àqueles que garantem o seu funcionamento cotidiano. Destacam que o 
apelo à ergonomia pode ser feito por diferentes atores da produção, mas que os ergonomistas seriam aqueles capazes de mobilizar conhecimentos e métodos em situações singulares. Além disso a ergonomia seria baseada na ação, que seria construída considerando-se critérios de saúde e de eficácia. Dentre os aspectos considerados sobre a ergonomia, denominada por eles de língua francesa, ressaltam a importância da construção do problema, conforme Wisner propôs em 1995 e a inclusão da atividade como um aspecto fundamental e diferenciador da abordagem. Outros temas fundamentais são tratados como a variabilidade e a diferença entre o prescrito e o efetivamente realizado. Reforçam a importância da articulação de diferentes pontos de vista no processo de ação e da sua deontologia. Tratam também dos conhecimentos existentes sobre o ser humano, sobre atividades estudadas, sobre normas, sobre a análise da atividade propriamente dita, entre outros temas. Descrevem e discutem a metodologia da análise ergonômica do trabalho e finalizam argumentando que na pratica ergonômica cada intervenção é uma construção, esta pode ser, em parte, antecipada, mas ela é sempre re-atualizada devido aos eventos que ocorrem.

Em seguida, no capítulo 21, François Daniellou, traz uma discussão sobre a condução de projetos de concepção de sistemas de trabalho. Neste caso, fica patente que a ergonomia evoluiu da proposição de recomendações para uma efetiva participação em projetos, onde o ergonomista precisa incluir uma abordagem da atividade futura dos trabalhadores que vão trabalhar na situação que está sendo concebida. Para tal ele vai se relacionar com diferentes atores da concepção e o autor discute as oportunidades e as dificuldades daí resultantes. Mostra que a base desta abordagem está na análise de situações de referencia que trará um repertório de situações de ação características que serão usadas para estabelecer uma ponte entre as atividades analisadas e as futuras, esses resultados servirão como referências para a concepção. Trata ainda da finalidade das simulações, como um prognóstico importante relativo ao trabalho futuro. As fases seguintes seriam a execução do projeto, a partida e a avaliação do projeto.

Em continuidade à discussão da ergonomia de concepção, Pascal Béguin propõe um capítulo onde o ergonomista é visto como um de seus atores. Para ele o desejo desses profissionais é se envolver nos processos de concepção para que tanto aspectos do funcionamento humano como as atividades sejam neles consideradas. Trata da possibilidade de que a ação se dê no projeto em si e na sua condução, onde haveria um papel importante a ser desempenhado. Nesse caso a sua atuação seria chave para ajudar na construção e na resolução do problema, assim como no aconselhamento de outros atores nesse processo, como o empreendedor e o coordenador do projeto. Trata ainda a questão da temporalidade desses processos, relacionando-a com as possibilidades para a incorporação de conceitos de ergonomia. Discute também a importância das situações de referência, da simulação e que a concepção continuaria no uso e seria distribuída entre os projetistas e aqueles que operam ou vão operar os sistemas. Finaliza o capítulo discutindo a diversidade dos pontos de vista, a busca da coerência, ressaltando os papeis possíveis para o ergonomista relacionando suas competências com as de outros atores nesse processo.

28 Fernande Lamonde discute as prescrições dos ergonomistas, mostra que essa questão é pouco discutida nos textos, nos livros de ergonomia. Partindo da constatação que esta disciplina não é unificada, os procedimentos prescritivos refletem a sua diversidade, faz referência à abordagem da atividade e a dos fatores humanos. Trata da ambigüidade existente ao se prescrever, seja como uma tentativa de impor um ponto de vista ou 
como um convite para a troca, para uma concepção compartilhada. Destaca quais seriam os objetos da prescrição em um processo de concepção, dentre eles, os dispositivos materiais, as regras, as instruções, os programas de computador, os espaços, os locais de trabalho, a organização do trabalho, a formação. Discute a relação com os projetistas e a importância das prescrições com um resultado embasado em uma análise da atividade, assim como utilizar resultados de estudos experimentais, procedimento típico da abordagem Fatores Humanos. Nesse caso seria importante confronta-las com os resultados da análise da atividade, pois esses permitem submeter as prescrições normativas a aspectos da realidade. Ainda reforça a importância da validação e do acompanhamento das soluções prescritas.

Françoise Darses e Florence Reuzeau tratam da questão da participação dos usuários na concepção dos sistemas e dispositivos de trabalho, destacam que essa prática já era comum na década de 1970 nos países escandinavos, mas cujo interesse se renovou e hoje se tornou uma prática mais corrente em outros países. Distinguem diferentes tipos de participação e que nesse tipo de processo estão em jogo os conhecimentos e racionalidades de atores e profissionais distintos, muitos dos quais nunca haviam participado em projetos. Discutem as motivações e as modalidades da concepção participativa, que vão desde a simples informação até um envolvimento efetivo nos processos de decisão. Definir, decidir quem participa e como atuam são questões centrais nesses processos. Destacam ainda a importância das ferramentas que auxiliam, dentre outros aspectos, a análise dos problemas, a simulação da situação futura, e a decisão coletiva. Tratam das dificuldades que podem existir e do papel que o ergonomista pode desempenhar em situações como estas e concluem relevando as mudanças conseqüentes a esses processos, como a propiciação de uma inteligibilidade mútua, a aprendizagem dos atores e as mudanças nas relações nas empresas.

30 Ainda no campo da concepção, Christian Martin redigiu um capítulo sobre o papel do ergonomista em projetos arquitetônicos. $\mathrm{O}$ autor da uma importância significativa à multiplicidade de atores implicados e diferentes problemas que podem existir, uma vez que conceber é partir de um problema mal definido e, também, contrariamente ao que ainda acredita-se, é um processo coletivo e não o resultado do trabalho individual de alguém muito capaz. Propõe uma metodologia que propicie ao ergonomista participar de diferentes fases do projeto arquitetônico e os desafios de tal empreitada. Reforça a importância que há na tentativa de definir os objetivos e formalizar aquilo que for possível. Por outro lado, mostra que o processo é algo a ser construído e que o procedimento por ser iterativo, é passível de correções e mudanças, dentro de limites. Trata das diferentes questões que se colocam no ante-projeto, no projeto, na construção e na entrega da obra. Ainda discute o posicionamento do ergonomista, dependendo de quem o convida para trabalhar as questões, os trabalhadores, o coordenador do projeto ou o empreendedor. Propõe que um dos papéis significativos que o ergonomista poderá exercer está relacionado à elaboração de esquemas diretores, pois estes permitem construir uma maior coerência entre os diferentes projetos das empresas ou estabelecimentos, atuando desde as suas definições estratégicas.

31 A concepção na área da informática é tratada por Jean-Marie Burkhardt e Jean-Claude Sperandio. No texto proposto eles definem que o campo de atuação diz respeito às atividades onde há uso de um sistema computadorizado e, dentre os temas apresentados podem ser evidenciados, o da divisão das tarefas entre os seres humanos e os computadores, a alimentação de sistemas especialistas em conhecimentos, a 
predição dos usos, assim como os processos de validação das hipóteses relativas à utilização ou ao comportamento dos usuários. Reforçam a importância para que se aprofunde o conhecimento do trabalho dos programadores, assim como a evolução da informática e a conseqüente demanda de novos estudos e investigações em ergonomia. Como desafios mostram os diferentes contextos e os focos de atuação, como, a aparência gráfica do sistema, a facilidade do uso e a relação do programa de computador com as tarefas que os usuários devem desempenhar. Dentre as possibilidades, ressaltam a plasticidade dos programas que, finalmente facilitaria soluções que aumentem a utilidade, a usabilidade, os riscos e a acessibilidade. Tratam ainda dos diferentes papéis do ergonomista e a variedade existente nos projetos e nas possibilidades de participação. Finalizam que o papel, assim como a responsabilidade do ergonomista tendem a crescerem, principalmente se ele atuar bem a montante no projeto dos sistemas informatizados.

32 Ainda na área da informática, Christian Bastien e Dominique Scapin escreveram um capitulo sobre a concepção de programas de computador interativos centrada no usuário. Para eles um sistema interativo de boa qualidade deve ser de fácil compreensão, ter seu uso facilitado, com uma conseqüente redução dos custos de formação e de assistência técnica. Esse processo de concepção deve ser iterativo e implica os futuros usuários desde a concepção. É necessário, portanto, conhecer as necessidades, as características dos futuros usuários e as suas tarefas, as restrições materiais e definir objetivos com relação à usabilidade do futuro sistema. Propõem três etapas básicas para esse processo, a da elaboração do modelo conceitual, o detalhamento relativo à concepção das caixas de diálogo e a organização de menus, por exemplo, e, finalmente um desenvolvimento em detalhes da interface. Por fim, é importante avaliar as soluções propostas, com a participação dos usuários, com relação ao uso, a maneira como interage com o sistema e suas opiniões. Um outro tipo de avaliação seria feito por especialistas, onde o sistema seria avaliado por especialistas em seus desempenhos, atributos e características. Trata-se, por exemplo, dos métodos de avaliação da usabilidade. Acreditam que nessa área ainda há muito para se fazer para que os programas de computador sejam melhores.

33 A ergonomia de produtos é tratada por Pierre-Henri Dejean e Michel Naël no capítulo 28. Fazem uma distinção da ergonomia de sistemas industriais e das condições de trabalho, pois estas se inserem numa lógica de empresa, de confiabilidade e produtividade, enquanto que a de produtos está inscrita numa lógica de mercado e de concorrência. Propõe uma conceituação de produto e como houve uma evolução que inclui o binômio produto-serviço prestado. Definem critérios ergonômicos, como a segurança, a eficácia, a utilidade, a tolerância a erros, as fases de apropriação por parte dos usuários, o conforto e o prazer. Aquilo que é propiciado pelo produto é fundamental sob o ponto de vista da ergonomia. Discutem a inserção do ergonomista nos processos de concepção em várias etapas, assim como o seu papel para acompanhar e avaliar o uso. Dentre os desafios ressaltam a importância das relações que se constroem nas equipes de projeto, as possibilidades de usuários, a diversidade e os tipos de funcionamento dos produtos, assim como a aceleração dos processos de concepção. Como conclusão, afirmam que há um processo comum de "contaminação" entre a ergonomia do produto e a do trabalho.

34 Jean-Claude Sperandio e Gerard Uzan propõem uma discussão sobre artefatos informáticos para pessoas com necessidades especiais. Discutem o conceito de 
"handicap" e os diferentes tipos de deficiências que podem ser minimizadas através de equipamentos. A ergonomia pode, segundo os autores, contribuir de maneira significativa nesse processo, isto se daria de várias maneiras, seja na concepção de equipamentos ou em mudanças nas tarefas. Com relação aos auxílios técnicos, discutem se a informática seria uma barreira ou um auxílio para ajudar essas pessoas. Ela pode ser muito útil ao se tratar da concepção de interfaces, próteses ou ainda robôs. Nesses casos, a ergonomia pode exercer um papel interessante, pois é possível agir em vários níveis é possível utilizar critérios clássicos de avaliação ergonômica desde o processo de concepção. Tratam especificamente dos auxílios para pessoas com dificuldades visuais, incluindo a noção de acessibilidade, principalmente para aplicações na Internet; no caso de pessoas com dificuldades de audição, discutem várias opções para ajudar as pessoas não apenas para poderem captar sinais, mas também para vencerem as barreiras na aprendizagem; para pessoas com dificuldades motoras, discutem diferentes auxílios de comando, de comunicação, entre outros. Ressaltam a importância dos desafios na área e os atrasos, principalmente no caso de pessoas que possuem deficiências mentais. Concluem discutindo a necessidade de adaptação para cada pessoa e, ainda que os resultados obtidos para pessoas com necessidades especiais podem ser úteis para o conjunto da população.

Com relação às contribuições da ergonomia para a prevenção dos riscos profissionais, Alain Garrigou, Sandrine Peeters, Marçal Jackson, Patrick Sagory e Gabriel Carballeda propõem uma discussão que inclui uma apresentação de conceitos gerais sobre o tema e conceitos oriundos da ergonomia. Com relação às suas possíveis contribuições, principalmente no que diz respeito ao fato que o enigma das condições de exposição dos trabalhadores aos riscos profissionais resiste às formulações feitas por especialistas em prevenção propõe, em um primeiro momento explicitar as abordagens clássicas em prevenção e seus limites. Em seguida discutem, a partir de uma visão da ergonomia, algumas saídas para esse dilema, como o fato de que o enigma da exposição precisa ser formulado coletivamente, ressaltam ainda a necessidade de se compreender as diferentes formas de variabilidade e a importância dos saber fazer de regulação e de prudência. As propostas são formuladas consideradas a partir das diferentes dimensões do humano, a biológica, a cognitiva, a psíquica e a social. Ressaltam o papel da análise ergonômica do trabalho, como uma articulação de abordagens objetivas e subjetivas e que a exposição aos riscos pode ser considerada como uma resultante de diferentes níveis de compromisso. Finalmente propõe que a modéstia neste campo é obrigatória e que os atores da prevenção devem se expor aos riscos da interdisciplinaridade.

A quarta parte do livro trata de modelos de atividades e dos domínios de aplicação em ergonomia.

Em seu capítulo, sobre a gestão de situação dinâmica, Jean Michel Hoc afirma que o controle de processo é um tema clássico de pesquisa em ergonomia e estaria nas origens da ergonomia cognitiva e que esses estudos evoluíram em direções diversas, sendo que uma estaria mais voltada para as relações entre humanos e máquinas em situações dinâmicas, onde os processos evoluem sob controle parcial daqueles que estão operando. Os interesses das pesquisas na área estariam voltados para orientar as modalidades de concepção e para ajudar em processos de formação. Trata ainda de aspectos cognitivos nessas situações, como a questão da supervisão e o controle, a velocidade como evoluem, a incerteza e o risco, as atividades que evoluem em paralelo e as diferentes maneiras como as pessoas compreendem e tratam as informações. Em 
seguida são apresentados sistemas de representação e tratamento, como sistemas causais, funcionais, topográficos e transformacionais. Há também uma discussão centrada na estrutura cognitiva, os objetivos da ação e como determinam as atividades, a questão das decisões e sua sub-otimização, ao ajuste freqüente e em paralelo dos planos de ação e a articulação entre diferentes níveis de controle (atividades simbólicas e sub-simbólicas). Conclui confirmando, assim como outros autores deste livro, a importância da inserção da pesquisa em ergonomia para a concepção destes sistemas de trabalho.

38 Janine Rogalski trata da gestão das crises em seu capítulo, consideradas como casos limite da gestão de situação dinâmica. Apresenta como define as crises e a importância da participação dos ergonomistas em interação com outros autores para estudar suas possíveis ocorrências e como lidar com um evento inesperado quando são excedidos os recursos pré-existentes, as possibilidades de ação, e cuja evolução tende a se estender. Discute as crises e sua gestão que está estreitamente ligada a um sistema de atividades, a usa organização, sua estrutura, suas competências, suas razões de ser, seus objetivos e seus valores. Chama atenção para a dimensão simbólica, o impacto que, eventuais acidentes causam na população. São apresentadas questões relativas à instrumentação em termos das ferramentas cognitivas disponíveis, as maneiras como os atores se organizam, os fluxos de informação nos dispositivos operacionais e os auxílios à condução das operações, mostrando como a gestão e o fluxo das informações é fundamental para o sucesso das operações. Discute a importância do compartilhamento de princípios comuns que permitiriam uma sincronização cognitiva e temporal, uma cultura compartilhada. Reforça a importância da contribuição da ergonomia, sobretudo para ajudar a conceber e prever, se antecipando às possíveis "entradas" na crise.

39 A assistência para as atividades de concepção é tratada por Françoise Darses, Françoise Détienne e Willemein Visser. Primeiramente discutem os desafios na área ligados, sobretudo à sua variabilidade. Mostram que as atividades de concepção requerem coordenação, cooperação, é um processo de decisões, exige evolução das competências, que cada vez mais é necessário que os usuários participem do processo e que é importante dar instrumentos para capitalizar os instrumentos da concepção. Tratam da relação processo prescrito e processo efetivo na concepção, do memorial descritivo às especificações. Ressaltam a importância de se conhecer as características gerais desses processos e como suportá-los, desde a busca para uma melhor definição dos problemas, da identificação das necessidades, da elaboração e da avaliação de soluções. A simulação é discutida também no que diz respeito às possibilidades de se ajudar a enriquecer as funcionalidades da avaliação cognitiva, por exemplo, quanto aos critérios (confiabilidade, usabilidade, estética), quanto às possibilidades e ao planejamento para a resolução de problemas. Reforçam ainda a questão da oportunidade para se propiciar sempre que possível a reutilização, aproveitar as experiências anteriores, como as bibliotecas usadas em engenharia de programas e computação e a "inteligência artificial". Uma outra vertente da questão está ligada à gestão de requisitos, como capta-los para poder elaborar o produto, quais são os objetivos, as especificações funcionais, os desempenhos esperados. Sempre que possível, o processo de concepção deve ser registrado para se ter uma memória daquilo que foi desenvolvido, inclusive para entender suas racionalidades, suas características cognitivas, principalmente nas situações coletivas de concepção. Tudo isso para ajudar a melhor estruturação desse tipo de modalidade de ação. 
40 As atividades de serviço são tratadas por Marianne Cerf, Gerard Valléry e Jean-Michel Boucheix. Os autores iniciam o capítulo tratando do amplo espectro da realidade de serviços e da crescente importância do setor na economia de muitos países e dos impactos da introdução de tecnologias de informação e comunicação nas suas operações. Tratam ainda da peculiaridade em serviços que é a participação do usuário ou cliente no processo. Além de ser um setor que tem merecido muitos estudos em ciências econômicas e sociais, este setor tem demandado cada vez mais estudos em ergonomia, como por exemplo, no que diz respeito à concepção das instalações e do trabalho. Há vários aspectos que têm impacto significativo no trabalho, como os objetivos, o tempo, os espaços, a co-dependência na relação de serviço e a relação entre o que é prescrito e o que acontece no desenrolar da interação, que é um processo de construção compartilhada entre os trabalhadores e os clientes / usuários. Discutem a importância dos estudos em ergonomia para a concepção da organização do trabalho, dos espaços e da formação profissional e para melhor construção de situações onde há uma relação entre a organização, os beneficiários e os prestadores. Por fim, os autores chamam atenção ainda para desafios mais recentes, com a redução e/ou o desaparecimento da relação direta entre o beneficiário e o prestador através de ferramentas de informática em vários tipos de serviços.

41 O trabalho de mediação e intervenção social é discutido no capítulo proposto por Robert Villate, Catherine Teiger e Sandrine Caroly-Flageul. Os autores mostram um cenário cheio de evoluções recentes e desafios, mostram a importância da emergência de novos tipos de trabalho que, ao lado de profissões mais tradicionais que têm, como características comuns, o fato de existirem para dar conta de necessidades sociais, de serem na maioria das vezes empregados pelo Estado, que além de se constituírem como relações de serviço são de serviço público, que é difícil recensear todos os tipos de atividades e pessoas ocupadas e que, muitas vezes, devido à emergência de dimensões sociais nesse tipo de ocupação e por atenderem populações em grande dificuldade não recebem uma preparação adequada. As exigências no trabalho social são múltiplas e há conflitos com a possibilidade ou não de mensurar as suas atividades. As competências não se resumem aos aspectos formais e pré-definidos, há nesse tipo de relação o risco de banalização, pois há falta de reconhecimento relativo ao que de fato fazem. Esses desafios também se colocam para a ergonomia e os autores tratam de vários aspectos que precisam ser considerados, em particular as demandas relacionadas com o “desgaste profissional". Propõem que sejam abordados, nas análises ergonômicas das atividades, os seus traços, a gestão do tempo, as diferenças entre o programado e o realizado, a importância da regulação coletiva, o uso de ferramentas que proporcionem uma "reconstrução das atividades", que sejam abordadas as disfunções, que se proponha uma co-observação ou auto-observação, entre outros. Em seguida, os autores propõem que sejam identificadas as situações de ação características, a gestão simultânea de ações distintas, a incerteza, os referenciais operativos comuns, o seu papel educativo e de convencimento, e as questões afetivas e os riscos para a saúde dos que trabalham com essas profissões. Finalizam deixando um questionamento significativo para a ergonomia, principalmente no que diz respeito aos mecanismos de exclusão existentes nas empresas e, é na maioria das vezes, com essas pessoas, excluídas do seu trabalho, que esses trabalhadores sociais lidam.

Christian Martin e Charles Gadbois escrevem sobre a ergonomia no hospital, tratam da evolução das abordagens que trataram das condições de trabalho, dos problemas físicos 
e das doenças como lombalgias para uma participação de ergonomistas em projetos de hospitais, numa verdadeira condução de projeto. Destacam alguns aspectos do sistema hospitalar e dos diferentes atores que nele trabalham. Destacam entre os desafios para abordar os problemas, as questões temporais que se estendem ao longo das vinte e quatro horas, dos problemas de coordenação das atividades, da pressão da urgência, do uso do próprio corpo para dar conta das solicitações das tarefas, da importância do trabalho em equipe, do trabalho constante com informações, do uso compartilhado das articulações no espaço, do uso em comum de ferramentas e materiais e da necessidade de disponibilizar a informação para a atuação de outros colegas. Destacam aspectos tão diversos e presentes nas atividades, como a ação usando materiais e equipamentos de tecnologia cada vez mais avançada, um verdadeiro trabalho de monitoração e controle de diferentes pacientes ao mesmo tempo, e a confrontação cotidiana com o sofrimento e a com morte. Por fim, discutem possibilidades de ação em ergonomia, desde a "formação-ação" para a análise das condições de trabalho até a participação na concepção arquitetônica destes locais.

43 A agricultura é tratada em um capítulo escrito por Marianne Cerf e Patrick Sagory. Nele, os autores, reforçam a importância do setor para as sociedades, ainda mais com a crescente preocupação dos consumidores com relação aos riscos alimentares e com a qualidade daquilo que é consumido, ainda, as exigências para que os agricultores preservem os espaços e que também reduzam a possibilidade de poluição, oriunda das práticas de cultivo. São tantas exigências para os agricultores, um ofício de competências múltiplas, que o estudo de seu trabalho tem sido cada vez mais fontes de demandas, fato que traz desafios significativos para a ergonomia. Os autores apresentam algumas ferramentas para analisar o trabalho em agricultura, onde as atividades variam de maneira significativa no tempo e no espaço e discutem modalidades de ação para melhorar o trabalho agrícola. Fazem referência explícita à importância da incorporação às práticas dos conselheiros (técnicos) agrícolas da questão da ergonomia, para que as soluções propostas sejam exeqüíveis e que a sua implantação possa ser feita pelos agricultores e trabalhadores rurais. Citam especificamente a questão do projeto das edificações, e como ajudar os atores no processo de reflexão e orientação das escolhas.

Francis Six discute a construção onde o canteiro de obras seria o centro do processo de concepção-realização. Nesse capitulo o autor discute o contexto sócio-econômico do setor, mostra que há uma grande diversidade de ofícios e de empresas especializadas em partes do processo e trata de questões ligadas às características da população de trabalhadores, dentre as quais, a tendência ao envelhecimento, a predominância de homens com poucos anos de escolaridade e a alta prevalência de problemas de saúde e de acidentes relacionados com o trabalho. Apresenta os processos de produção na perspectiva de sua organização, como as etapas se desencadeiam e os seus atores e uma questão, considerada central, que seria a articulação entre a concepção, a instalação do canteiro e a construção em si. Com relação às atividades de trabalho no canteiro, mostra a articulação de variáveis, a importância dos papéis de diferentes atores, a grande variabilidade existente, a relação entre as chefias com as equipes e as articulações nos coletivos de trabalho. Por fim, discute o papel do ergonomista na dimensão do trabalho real dos atores.

45 A condução de automóveis é discutida por Jean-François Forzy. Há, no capítulo, uma apresentação do desenvolvimento e da democratização do seu uso, seja para fins de 
trabalho ou para uso pessoal / familiar. Há uma série de desafios para se melhor conhecer o que se passa no processo de condução, o autor faz menção ao caráter multitarefas, os constrangimentos de tempo que afetam o desempenho do condutor. Discute a importância da solicitação visual nesta atividade e da constante atenção e, também a dos tratamentos cognitivos, conscientes e pré-conscientes, para o sucesso das ações, do desempenho dos condutores. Mostra que há uma constante gestão do risco e que o comportamento das pessoas nestas situações é voltado para a regulação, evitando os acidentes, também trata aí de aspectos subjetivos. $O$ autor relaciona também a evolução da atividade com a introdução de diferentes artefatos, frutos do desenvolvimento tecnológico mais recente que, em princípio, servem para auxiliar a condução e algumas perspectivas para o futuro.

A ergonomia e a segurança em transportes são apresentadas por Claude Valot em seu capítulo. Aqui também há uma grande variedade de contextos e, segundo o autor, há muitas possibilidades de atuação para a ergonomia no setor. Os desafios são muito grandes, vista a importância das dimensões econômicas e afetivas, da quantidade de trabalhadores envolvidos com essas atividades, sejam aéreas, terrestres ou navais e, ainda a constante busca para redução dos tempos de deslocamento através do aumento da velocidade dos artefatos e do necessário aumento da confiabilidade dos sistemas. Aponta que a ergonomia tem um papel importante para reduzir o risco de perdas de vidas humanas, através do entendimento de problemas, de possíveis causas de acidentes e a sua dinâmica, estudando em profundidade os possíveis determinantes e considerando também o aumento significativo de operações no setor e as suas transformações constantes. Há uma apresentação relativa a modelos para análise, seguida de uma série de questionamentos relativos à segurança, à proteção, à redução de acidentes para preservar a vida. Há ainda um debate sobre a questão do papel da ergonomia com relação ao tempo ganho com o objetivo de tornar compatíveis as capacidades humanas e os dispositivos de controle e condução dos meios de transporte, principalmente no que diz respeito à rapidez, à duração e à quantidade de pessoas transportada. Por fim faz menção à tensão resultante para os operadores e à necessidade de se aproximar a necessidade de se ganhar tempo e de se preservar a vida.

A edição em língua portuguesa do livro conta com mais quatro capítulos, o primeiro propõe uma discussão sobre ergonomia, formação, transformação e foi escrito por Marianne Lacomblez e por Catherine Teiger. Elas propõem uma primeira questão que relaciona a ergonomia com um processo de transformação das pessoas através da formação, pois ela seria uma dos motores que permitiriam contribuir com os processos de concepção, de construção da saúde, com o reconhecimento das competências, da transmissão de experiências e com o desenvolvimento profissional. Afirmam a importância desses processos para reforçar os mecanismos de cooperação entre os diferentes atores, sejam eles engenheiros, conceptores (projetistas), representantes de trabalhadores, participantes em comissões, entre outros. Dentre os objetivos destes processos de intervenção-formação, citam a importância do reconhecimento dos saberes dos operadores, a necessidade de se partir daquilo que já conhecem os participantes e da apropriação de conceitos e métodos de análise do trabalho, a linguagem para facilitar as trocas, a ação e a reflexão e a aprendizagem recíproca. Há um extenso desenvolvimento sobre questões fundamentais nesses processos, e fica patente a importância do reconhecimento da experiência de cada um dos participantes. Mostram também que não se trata de um processo fácil, pois há muitas dificuldades para se construir uma intervenção participativa e, também para se vencer barreiras, 
como quando se trata de questões ligadas ao risco e à organização das empresas. Ainda reforçam que a análise ergonômica do trabalho pode ser considerada como um instrumento da formação, principalmente porque permite que os integrantes façam a experiência em um processo de ação e reflexão. Tratam ainda da necessidade que o formador tenha também uma postura clínica, isto é, que esteja atento à evolução da palavra dos atores e que saiba congregá-los nesse processo de formação, adotando uma postura estratégica. Concluem afirmando que a transformação das pessoas e dos sistemas de produção são duas facetas indissociáveis da mesma moeda.

A seguir Elias Apud e Felipe Meyer propõem uma discussão sobre a ergonomia no trabalho florestal. Partindo de um ponto de vista próximo da fisiologia do trabalho, discutem a qualidade de vida em acampamentos florestais, certas características da população de trabalhadores, da organização e divisão do trabalho, assim como de técnicas do trabalho. Fazem uma discussão sobre pausas e sobre a rotação de funções para reduzir a carga de trabalho.

49 Fausto Leopoldo Mascia traz um capítulo referente ao trabalho da supervisão, da hierarquia intermediária. $\mathrm{Na}$ sua discussão mostra características deste tipo de atividade e o seu papel central como articulação entre diferentes níveis e nos mesmos níveis de trabalho em uma determinada organização. $O$ autor mostra que, na literatura são tratados diversos aspectos ligados a esse tipo de trabalho, mas não há praticamente referências à atividade desses trabalhadores, suas dificuldades, seus constrangimentos. Há referências à evolução histórica desse papel social e, dos desdobramentos mais recentes resultantes de mudanças organizacionais onde a sua própria existência tem sido questionada. $O$ artigo enfoca a multiplicidade das tarefas desses trabalhadores, agrupando-as como relacionais, de gestão, técnicas e comerciais. Há também uma proposta para que se incorpore o ponto de vista da teoria da complexidade para melhor entender aquilo que ocorre, como um processo de gestão de um sistema complexo, como uma atividade de integração e de contínua reconstrução para manter o sistema operacional em condições de alcançar os objetivos. Reforça que este trabalho é invisível e muito importante para o desempenho da empresa.

Por fim, há um capítulo sobre a ergotoxicologia (Laerte Idal Sznelwar), onde são tratadas as questões da exposição a substâncias químicas. Há uma discussão sobre os propósitos deste tipo de abordagem baseada na análise ergonômica da atividade, principalmente no que diz respeito à necessidade de se conhecer melhor o que se passa para poder evitar os riscos de intoxicação no curto e no longo prazo. É proposto um diálogo com disciplinas próximas, como a psicodinâmica do trabalho, a toxicologia, a medicina do trabalho, a epidemiologia, a higiene e segurança do trabalho, visando o enriquecimento de pontos de vista. São tratados aspectos dos trabalhos de prevenção tradicionais e a importância de se incorporar a abordagem da ergonomia para tratar dessas questões, pois ela permite um conhecimento aprofundado sobre o trabalho efetivo. São também discutidos alguns conceitos sobre saúde, sobre toxicologia do trabalho, sobre vigilância epidemiológica, entre outros. A seguir é feita uma proposta sobre o que consistiria uma abordagem em ergotoxicologia e há uma conclusão focando os desafios para que se incorpore este ponto de vista enriquecido com os desenvolvimentos mais recentes em ergonomia.

51 À guisa de conclusão

52 Através da leitura deste livro, várias questões podem ser elucidadas e outras suscitadas. A extensa bibliografia presente nas referências bibliográficas usadas para a constituição 
de cada capítulo poderá ser um guia muito útil a todos que queiram aprofundar os seus conhecimentos em ergonomia. Acredito ainda que haja uma "contaminação" cruzada entre idéias contidas ao longo dos textos. Mesmo quando, aparentemente, o interesse se atenha a um tema específico, o leitor encontrará informações muito interessantes em outros capítulos, inclusive há uma chamada ao final de cada um para que a leitura tenha continuidade em outros.

As idéias expostas permitem tecer uma relação entre elas, por vezes, é possível também evidenciar pontos de vista diversos que ajudam a enriquecer os debates e, permitem aos leitores se apropriarem ainda mais da riqueza hoje existente no campo da ergonomia e em áreas afins.

Um outro aspecto relevante é a sua utilidade para projetos. Há, em várias partes dos textos, subsídios significativos que podem ajudar equipes que participam de projetos em vários setores da economia, a obter melhores resultados, principalmente no que diz respeito às possibilidades de uso por uma grande variedade de pessoas, permitindo o desenvolvimento profissional, o conforto e a saúde. Acredito que há, nesse texto, bases sólidas para ajudar a promover o desenvolvimento e, sobretudo a inovação relacionada a modelos de organização, ao conteúdo das tarefas, às tecnologias da informação, às ferramentas de trabalho e aos mais diversos setores da produção expostos neste livro.

Paradoxalmente apesar de todo esse avanço, uma vez que este livro reflete uma parte significativa do desenvolvimento da ergonomia nos últimos 50 anos, o trabalho real, ainda é pouco conhecido. Ainda se confunde ergonomia com uma ciência voltada exclusivamente para questões físicas do trabalho, ao esforço, à postura. As idéias presentes no texto deverão ajudar a mudar esse ponto de vista, profissionais poderão embasar mais a sua ação para poder agir como agentes transformadores do trabalho. Responsáveis nas mais diversas instituições e empresas poderão se dar conta de uma série de benefícios que poderão auferir se introduzirem a ergonomia como um dos pressupostos fundamentais para o projeto da produção e de produtos e, também como um pressuposto da organização do trabalho e da gestão de operações. Esse livro poderá ser muito útil para os mais diferentes tipos de organizações, em particular, as governamentais, patronais e de trabalhadores para auxiliá-las em suas ações para melhorar o trabalho.

Compreender e respeitar o papel dos seres humanos, dos sujeitos, para a produção de bens e de serviços é um ponto fundamental, incontornável para o desenvolvimento de uma sociedade. $\mathrm{O}$ trabalho pouco conhecido e, infelizmente pouco reconhecido, é base de qualquer sociedade. $O$ desenvolvimento de uma sociedade não pode se basear em sofrimento, em doenças e em acidentes ligados ao trabalhar das pessoas. $\mathrm{O}$ trabalho decente, que permite a promoção da saúde, o desenvolvimento profissional e resultados significativos em termos de qualidade e produtividade é um objetivo que deve ser atingido o quanto antes para qualquer sociedade preocupada de fato com o desenvolvimento.

Boa leitura. 


\section{BIBLIOGRAFIA}

Falzon, P. (Ed.) (2006). Ergonomia. São Paulo : Edgard Blücher, (edição aumentada do livro :)

Falzon, P. (Ed.) (2004). Ergonomie. Paris : PUF.

\section{AUTOR}

\section{LAERTE IDAL SZNELWAR}

Departamento de Engenharia de Produção da Escola Politécnica da Universidade de São Paulo Avenida Professor Almeida Prado, nº 531, 05508-900 Cidade Universitária, São Paulo Brasil laertesz@usp.br 